\title{
PELA RUGOSIDADE DA VIDA: A SOLIDÃO E A ESCRITA COMO ROTAS DE FUGA EM JULIANO PESSANHA
}

Maraíza Labanca*

RESUMO: Pretende-se aventar, a partir das noções de "vida singular" e "solidão absoluta" desenvolvidas por Gilles Deleuze e Peter Pal Pelbart, como a escrita literária e a solidão funcionam como rotas de fuga diante do $e u$ e de modos de vida estabelecidos nas obras de Juliano Pessanha.

PALAVRAS-CHAVE: solidão, singularidade, eu, heterotanatografia, literatura contemporânea. *maraizalabanca@gmail.com

Doutoranda - Teoria da Literatura e Literatura Comparada - UFMG

ABSTRACT: Starting from the notion of "singular life" and "absolute loneliness", elaborated by Gilles Deleuze and Peter Pal Pelbart, it is intended to discuss in this article how the literary writing and the loneliness work as escape route before the self and before established ways of life in Juliano Pessanha's books.

KEYWORDS: loneliness, singularity, self, heterotanatography, contemporary literature 
1. PELBART. Prefácio, p. 15.

2. Trecho do poema "Método", de Julia Panadés, publicado no jornal mineiro de literatura e outras artes Pausa, junh de 2003. "Para além/ do
funcionamento pleno/ o fracasso/ é também um modo/ de ir".
"Quanto mais eu falo, mais eu sufoco o que me pede atenção: sou um acumulador de opacidades."

"Porque o amor transcendeu a ilusão amorosa, eu pude ver teu rosto: ele era a solidão de uma fogueira num descampado imenso e sem contorno.

Ao testemunhar tua aparição, descobri que a proximidade, a mais intensa, se dá junto da distância mais distante.

"Quando eu cheguei ao mundo nada mais tinha o benefício da chegado. A 'rugosidade da vida' tinha sido esticada até a extremidade onde o jorr das horas dá lugar à eternidade da cena. Assim, ameaçado pela linha de um ocaso, busquei a literatura e debrucei-me nos diários [...].

Juliano Pessanha

Em prefácio à Certeza do Agora, Peter Pal Pelbart assinala que Juliano Pessanha faz da escrita de uma vida "um instante de celebração, um acontecimento jubiloso, uma meditação ziguezagueante em que a palavra e o abismo passam a pertencer-se mutuamente, assim como a noite e a vida" ${ }^{\text {. Nos }}$ livros, o abismo avança sobre as figuras e sobre a língua de Pessanha, dissolve o sujeito, que aceita mergulhar na noite da sua ausência. Veremos que o abismo da solidão e o abismo da escrita em carne viva são as rotas de fuga que perfazem, para Juliano, um "modo de ir"2.

\section{MODOS DE VIDA}

Se voltarmos um pouco no tempo, verificamos que uma certa noção de subjetividade protagonizou o pensamento filosófico da modernidade, orientando, desde Descartes, uma racionalidade ordenadora do mundo. "A modernidade, então, se caracterizará pelo período de afirmação do sujeito, que, através da sua consciência pensante, estabelecerá uma ordem nos processos de representação da realidade"3. Estavase sob o jugo e o poder da razão humana: delineava-se um sujeito constituinte - como unidade, essência, universalidade - e um eu centralizador que, a partir do século XX, colide-se com seu próprio esgotamento. A subjetividade assim entendida é, nesse momento, abalada pelo que foi chamado de "crise do $e u$ ", desestabilizando o império da racionalidade.

Houve aí um passo, um passo em direção ao fora. Passo dado também no campo literário: enquanto desconstruía a lógica cartesiana, parte da filosofia do século XX ressaltou ainda o poder da escrita literária de fazer escapar das tiranias do $e u$, ajudando a romper a imagem clássica de um sujeito logocêntrico e idealizado ${ }^{4}$.

Paradoxalmente, no entanto, nas últimas décadas, verificou-se uma multiplicação das narrativas de si, dos relatos autocentrados, seja nos suportes virtuais - blogs, microblogs, redes sociais -, seja nos veículos impressos - autobiografias, diários e gêneros afins. Esse fenômeno não se desvincula
3. JARDIM. Impessoalidade e modos de vida em Gilles Deleuze: breves considerações, p. 2.

4. Tal processo culminou em obras de Michel Foucault, Gilles Deleuze, Roland Barthes e Maurice Blanchot em torno de uma escrita incapaz de restituir o autor como centro de emissão de uma voz. 
5. PELBART. Vida capital, p. 13.

6. PELBART. Vida capital, p. 20.

7. “O novo capitalismo em rede, que enaltece as conexões, a movencia, a fluidez, produz novas formas de exploração e de exclusão, novas elites e novas miserias, e sobretudo uma nova angústia - a do desligamento"
(PELBART. Vida Capital, p. 21). de uma prática acentuada no homem moderno: o consumo, conforme formulou Peter Pal Pelbart (2009), não só de bens materiais a todo custo, como - e principalmente - de bens imateriais, no que se incluem modos de vida estabelecidos e modos de engessamento desse $e$.

Modos de vida são consumidos a todo tempo e, junto a eles, há uma saturação de imagens e falas que registram, formulam e repassam esses bens: "a vida mesma tornou-se um capital"5: "Afinal, o que nos é vendido o tempo todo, senão isto: maneiras de ver e de sentir, de pensar e de perceber, de morar e de vestir? O fato é que consumimos mais do que bens, formas de vida - e mesmo quando nos referimos aos estratos mais carentes da população, ainda sim essa tendência é crescente".

Consumimos maneiras diversas de engendrar a subjetividade. No que pode ser chamado de capitalismo conexionista, a vida em sua singularidade - isto é, aquela que apresenta o traçado de rotas de fuga capazes de efetivar modos de vida desviantes - é expropriada em função de um bombardeio de imagens e falas que, em nome da conectividade, provoca precisamente uma consequência reversa: o medo do desligamento ${ }^{7}$. De acordo com o que avalia Pelbart, o desejo é posto: estar conectado; e também o seu risco: desligar-se, ser excluído. Sem perceber, vagamos numa rede que sustém a sensação de uma perpétua comunicação junto ao logro de uma garantia de inclusão, de identificação, de pertença, e, por fim, o escamoteio da solidão.

Os sujeitos levados pelo excesso de comunicação enredam-se na contínua exigência de alimentar esse excesso e também se põem a falar sem parar. Sem se dar conta, submetem-se à imposição de um perene expressar-se - na modalidade oral ou escrita -, mas tal prática é esvaziada de qualquer potência de criação ou, pelo menos, desejo real de dizer. O excesso de falas que inunda o mundo cotidiano, nas ruas, no trabalho, em casa, extingue a possibilidade de surgir algo que merecesse ser dito: um dizer "raro", "rarefeito", como apontou Gilles Deleuze em Conversações".

Tal contexto justifica a necessidade de voltar a levantar o lugar da solidão e da escrita como o que faz ressurgir a possibilidade de ter algo a dizer. Para Deleuze, o que importa é arranjar "vacúolos de solidão e de silêncio"9 que perfurem a conectividade exacerbada, trazendo à tona novamente o incômodo - ou mesmo o transtorno - da linguagem, suprimido nesse excesso. A isso o filósofo chamará "solidão absoluta" ${ }^{10}$; em resumo, aquela que reformula as possibilidades de relação, por meio de um contato que não se dá pela delimitação de um eu e suas identificações com um outro que é sempre o mesmo.
8. Cf. DELEUZE. Conversações. p. 166.

9. DELEUZE. Conversações. p. 166.

10. DELEUZE apud PELBART. Como viver só, p. 265. Em contraste à "solidão negativa", ela seria a solidão "povoada" de encontros, "nossa unica chance para todas as combinaçoes que nos habitam" (DELEUZE apud
EM TESE

N. 1

JAN.-ABR. 2013

LABANCA. Pela rugosidade da vida: a solidão e a escrita como rotas [...]

P. $76-84$ 
11. Cf. PESSANHA. Instabilidade perpétua, p. 26.

12. RAMOS. Ó, p. 130

13. DELEUZE. Crítica e clínica, p. 13

14. STAROBINSI, Jean-Jacques Rousseau. A transparência e o obstáculo, p. 188.

\section{EMERGÊNCIA DO CORPO}

É possível afirmar que Juliano Pessanha, autor paulista contemporâneo, com uma trajetória pelo pensamento filosófico, escreve contra a produtividade da língua ou a industriosidade gestual que adestra a dor e mutila modos de vida desviantes. Isso porque procura reservar à escrita o lugar da incandescên$c i a^{11}$ encontrada nas singularidades, o lugar onde viriam habitar "uns restos de vontade e de pasmo"12 não cooptados pelo "falso vivo" - ou seja, a vida que se consome, inflacionada por dizeres que represam o que ainda não foi dito.

Assinala em suas obras a possibilidade de uma escrita não mais comprometida com o delineamento de um eu: ela "não consiste em imaginar ou em projetar um eu"13. Procura recorrer, desse modo, a um tratamento da linguagem e da vida diverso do que é encontrado nas narrativas de si, a fim de gerar o que ele chamou de heterotanatografia - dando vida ao que permaneceu incubado ou ausente. Assim, as figuras de Pessanha testemunham uma vida que não é a considerada "social", abandonando e corroendo a exigência de uma subjetividade "bem formada". Desiste-se de simplesmente recuperar vivências ou de tomar posse de si mesmo, como queria, por exemplo, Rousseau em suas Confissões, ao confiar na possibilidade de uma interioridade transparente e dar vazão, pelo menos inicialmente, ao "espetáculo de sua própria consciência"14, aventurando-se na prática de perfilar um $e u$.
Gilles Deleuze (1997) declarou, em "A literatura e a vida", que "escrever não é certamente impor uma forma (de expressão) a uma matéria vivida. [...] Escrever [...] extravasa qualquer matéria vivível ou vivida"15. Para o filósofo francês, a literatura se faz com aquilo que vem dissolver o sujeito. Nesse sentido, a consciência deixa de ser o horizonte de produção e algo se constrói a partir do abismo em que o eu se perdeu, se esfacelou, rompendo com poderes e saberes que restringem o que fazemos, pensamos e dizemos. Na escrita de Pessanha, o desfazimento do sujeito é o ponto de partida. Mas o que significa desfazer um eu? É o próprio autor quem lança a pergunta:

Como é que se interrompe a avalanche autobiográfica e fictícia do eu? [...] E a resposta é: pela emergência do corpo. Pelos acontecimentos que tocam e fisgam um corpo exposto... Ali onde alguém é tocado e atravessado para além de todo e qualquer funcionamento racional, ali onde um espinho tocou a carne e onde uma questão insiste em forma-de-ferida, ali é o lugar onde o "eu" deve mergulhar e deixar-se desmanchar ${ }^{16}$.

Deseja-se chegar ao cimo dos acontecimentos ou à rugosidade da vida, a fim de fazer retornar a celebração, a inauguração das coisas do mundo, possível pela solidão e pela palavra literária, "espaços desmobilizados"17 em que o mundo não é normalizado, não sofreu a "amputação gigantesca
15. DELEUZE. Crítica e clínica, p. 11. Juliano Pessanha, em um ensaio do livro $A$ certeza do agora, afirma que "Vivência $[$... é uma espécie de alcoolismo existencial. Na vivência, o vivido está sob inteiro controle do 'eu'. está sob inteiro controle do 'eu'. de auto-relato, apenas engorda de auto-relato, apenas engorda determinada" (PESSANHA.

Certeza do agora, p. 97).
16. PESSANHA. Instabilidade perpétua, p. 67.

7. Cf. PESSANHA Instabilidad Perpétua, p. 70. 
18. PESSANHA. Instabilidade Perpétua, p. 67.

19. PELBART. Como viver só, p. 268.

20. PELBART. Como viver só, p. 268. das possibilidades humanas" ${ }^{18}$. Nos poemas e aforismos do autor, a celebração das coisas do mundo torna-se ainda mais intensa, cada uma é tomada em sua "epifania permanente" uma pétala desgarrada, um hino, a quebra da onda, a crina avermelhada de um cavalo.

As figuras que atravessam os textos de Pessanha parecem arrancar um poder de reação automatizado presente nos pactos sociais, traduzindo, assim, "a recusa de uma sociabilidade envenenada" ${ }^{19}$, a resistência aos hábitos territorializantes. Gombro, K., Z., claras alusões a Franz Kafka e a Witold Gombrowicz, falariam algo dessa vida associal, trazendo à baila um "exílio interno" do homem e a palavra que se quer desvencilhada das contenções, ainda que, muitas vezes, precária em sua rarefação. Tanto a língua como o sujeito que dela faz uso parecem ir em direção a um limite - das possibilidades de comunicação e dos modos de vida estabelecidos detonando "o pacto da universal hipocrisia que assegura nossa existência social e cotidiana" ${ }^{20}$ e o comércio das relações.

\section{DESEMBRULHAR A DOR, ESCREVER}

No texto "Como viver só", de Peter Pal Pelbart, é convocada uma solidão que não é solipsismo: não se trata da solidão conforme entendida pelo senso-comum, isto é, ela não significa um fechamento dentro de um $e u$ inchado e incapaz de se dedicar à tarefa de não-ser-eu, um eu que quer manter

EM TESE v. 19

N. 1 o corpo intacto. Esse corpo-só seria lavado das complicações do mundo e cravado num lar monástico que impede qualquer abertura ao outro em sua outridade. A solidão de que fala Gilles Deleuze é, ao contrário, uma solidão que não se dissimula numa reclusão altamente conectada às redes de comunicação. Ela é, sim, um modo de escape que Pessanha constrói para, a partir daí, deixar brotar outras modalidades de encontro.

Acessar a essa solidão absoluta, para Juliano, relaciona-se a um certo retorno à infância, no entanto não exatamente pela via da reminiscência, mas pela criação de um outro. A memória de uma vivência, ainda que incidente, aparece para realçar a morte da criança possível. O relato da morte da criança dá espaço, ao mesmo tempo, para a recriação da vida: por meio da escrita, refazem-se os caminhos que foram obliterados no percurso dos anos, para tornar possível um novo nascimento.

A criança está morta e é encontrada na escrita que retoma a "noite de minha ausência" ${ }^{21}$, denuncia a fraude a que o sujeito é submetido ao aprender a dizer $e u$ diante de um outro- cópia e para de afundar-se no informulado de uma íntima questão, enganando-se no excesso de respostas dadas por aqueles que o rodeiam. O pensamento de Gombro converge, então, para o ponto: "Como é possível esta vida?" 22 e tenta abordar o enigma, sabendo, de antemão, que não se pode
21. PESSANHA. Certeza do agora, p. 63.

22. Essa pergunta aparece em vários momentos da obra de Juliano Pessanha. 
23. Cf. PESSANHA. Certeza do agora, p. 75.

24. Ver nota 36 25. "[...] a palavra da escritura
é a palavra que despenca" (PESSANHA. Certeza do agora, p. 29).

26. "Os absolutamente sós" é o título de um dos livros de Lúcia Castello Branco, referência a um excerto da obra da autor portuguesa Maria Gabriela Llansol: "trabalhar a dura materia move a língua; viver pouco, os absolutamente sós". Cf. CASTELIO BRANCO Os absolutamente sós, p. 12

27. Cf. PELBART. Prefácio, p. 14-15. respondê-lo. Abordar o enigma, afundar no informulado de uma questão é também, nessa escrita, dar lugar à dor sem forma, cujo desconforto apontaria a zona da incandescência Escrever é, para ele, desembrulhar (ess)a dor ${ }^{23}$, pela emergência do corpo. Em carne viva.

Não se trata, então, nos textos de J. Pessanha, de alcançar uma resposta; é outra a direção apontada pela escrita assombrada do autor. Assombrada tanto no sentido de uma escrita que não tapa os olhos para o terrível, antes os revira ${ }^{24}$, numa tentativa insana de reencontrar a criança perdida; como no sentido de uma escrita da sombra, da noite. Por isso não se pode fazer outra coisa a não ser incorporar a sua questão e mover-se com o corpo meteórico da palavra "que despen$\mathrm{ca}{ }^{25}$, palavra que, por extensão, passar a interrogar a existência de tudo, os homens, as coisas, o fenômeno do mundo Para interrogar as coisas, é preciso, porém, simultaneamente celebrá-las, uma a uma, como a um evento inaugural. Ser aberto - propiciar a aparição, visar ao fora.

O homem blindado, de dentro, ao contrário, segundo escreve Pessanha, toma a vida como um fato previamente determinado, para ele, o acaso é retido num pote de conserva O homem de fora, ou a criança, ou o escritor, ou o "absolutamente só" ${ }^{26}$ fala a partir do seu deserto ${ }^{27}$, deve valer-se da palavra despencada, "pois nela o homem dá testemunho do surto-susto de sua aparição e nela o homem se aninha no lugar do assombro"28. Contra a palavra industrializada, portanto: aquela que desabou.

\section{ROTAS DE FUGA}

Na seção "Esse-menino-aí", que compõe o livro Certeza do agora, o narrador reelabora a infância do menino Gombro "um bebê abordado pelo cálculo"29 -, e a maneira como esse menino foi, por todos os lados, assassinado, pouco a pouco, pelas instâncias socializadoras chamadas educação, família, medicina. Todas colaborando para a formação de uma fraude futura - o menino decorava fórmulas na escola e fórmulas para a vida social até desconhecer a "rota de fuga" 30 . Com isso, por muito tempo, a "região da vida possível" ${ }^{31}$ permanecia intocada, faltava-lhe algo clandestino, como a solidão do que se ama sozinho. Exteriormente, no entanto, “[...] fui uma criatura totalmente exemplar e sem defeitos. Minha mãe esperava de mim um futuro feito de glória e de poder; aos seus olhos eu era uma espécie de pequeno Midas, jamais dera problemas e o que eu tocasse era ouro"32. O condicionamento exemplar para a vida social dissimulava, entretanto, o aniquilamento da criança em sua singularidade. Ao expor a morte do menino, o texto expõe ainda o $e u$ na sua condição de simulacro - construção artificial para sanar as demandas da vida em sociedade.
28. PESSANHA. Certeza do agora, p. 29.

29. PESSANHA. Certeza do agora, p. 41.

30. PESSANHA. Certeza do agora, p. 43.

31. PESSANHA. Certeza do agora, p. 44.

32. PESSANHA. Certeza do agora, p. 49.

EM TESE $\quad$ BELO HORIZONTE $\quad$ v. $19 \quad$ N. $1 \quad$ JAN.-ABr. $2013 \quad$ LABANCA. Pela rugosidade da vida: a solidão e a escrita como rotas [....] $\quad$ P. 76-84


33. PESSANHA. Certeza do agora, p. 50

34. PESSANHA. Certeza do agora, p. 52.

35. “Eu revirei os olhos sem parar madrugadas inteiras $[\ldots] "$.

(PESSANHA. Certeza do agora, p. 53.)
Por que sobrevivem "os falsários, os que se identificam com a criança morta?" ${ }^{3}$, pergunta Gombro. A vida entoada pela causalidade, pela competência dos saberes instituídos, dos comportamentos engessados, toda a "dedetização" empreendida pelo mundo que o acolheu em suas formas organizadas levaram-no à solidão dos que escapam num deserto íntimo, numa angústia sufocada pelo que se costuma chamar de real: "Eu fiquei mais só. Eu fiquei nos anéis de Saturno, eu fiquei andando na garganta de Netuno, eu fiquei nas ruas vazias do Morumbi”34. A criança aprendera, do fundo de sua vazia e vasta solidão, a revirar os olhos sem parar, na ilegalidade escura do seu quarto ${ }^{35}$.

$\mathrm{O}$ ato de revirar os olhos, junto ao de, mais tarde, escrever remonta uma tentativa de dar passagem à criança perdida dando-lhe a chance de, pela escrita, aceder a um novo nascimento. Entretanto o que nasce não chega a ganhar uma forma, permanece indefinido, sem nome. Trata-se de um processo de dessoterramento desse menino, o que ocorre junto a um processo de dessoterramento da palavra. Haveria, em outro lugar - talvez o da infância, o da escrita, o da solidão - um andamento irregular dos afetos e a utilização das palavras destituídas de um discurso que faz liame, liame social. Isso porque as palavras tagarelas, sedentas de sentido, estão em toda parte. Barulhentas, são esquecidas de seu próprio ser de palavra, de seu chiado, de sua falha primordial que aponta o fracasso da comunicação, o fracasso dos vínculos. O limbo da linguagem.

O homem de fora revira os olhos a fim de ver o invisível e ouvir o inaudível e, assim, já escreve, deixa ser vigiado pelo abismo que o informula e o decompõe, tornando-o um "elemento vazado e, na condição de elemento vazado, incapaz de erigir qualquer identidade" ${ }^{36}$. Com isso, esgarçam-se os contratos sociais, a lei, o bom-senso, o bom entendimento e ressalta-se um dizer que agoniza frente à sociedade contemporânea. A solidão e a escrita seriam, nesse sentido, maneiras de desapropriar o homem de uma comunitária sobrevivência que, por todos os lados, restringe a vida possível.

\section{PELA RUGOSIDADE DA VIDA}

Mais uma vez é Deleuze que nos fala da literatura como um empreendimento de grande saúde: aquilo que, próximo a um limite da língua, consiste em "[...] libertar a vida em toda parte onde esteja aprisionada pelo homem e no homem, pelos organismos e gêneros e no interior deles" ${ }^{37}$. Para libertar a vida pela escrita literária, segundo o filósofo francês, é preciso que haja uma destituição do poder de dizer $e u$, dispensando a elaboração das lembranças que atente para uma legibilidade corrente, destra. Se o eu é posto de lado, tenta-se elaborar o que, paradoxalmente, permanece mal formulado, porque realça o aberto, o vazio do sentido, os interstícios das
36. PESSANHA. Certeza do agora, p. 73.
EM TESE
BELO HORIZONTE
v. 19
N. 1
JAN.-ABR. 2013
LABANCA. Pela rugosidade da vida: a solidão e a escrita como rotas [...]
P. $76-84$ 
38. Segundo os textos de Pessanha, se se é visitado pela criança que não pôde ser, como acontece a Gombro, a criança desfaz o adulto identificatorio e expoe a morte a que foi destinado. Nesse momento, a "tensão do pressentimento explodia, o corpo (imensamente solitário, imensamente autistico) era varrido pelo estremecimento" (PESSANHA Certeza do agora, p. 79.).

39. PESSANHA. Certeza do agora, p. 56

40. PESSANHA. Certeza do agora, p. 56. formas identificatórias que engendram o mundo adulto ${ }^{38}$. Trabalhar sobre o informulado torna os livros, por extensão, uma soma de gêneros dispersos e mal resolvidos (ensaios, poemas, aforismos, contos, heterotanatografias...). Com o corpo meteórico da palavra desacostumada, "que despenca", deseja-se acessar o fora, aberto ao homem desterrado, plantado apenas em sua própria inquietude, corpo que fala a partir de um desassossego que inaugura e assombra o mundo e a linguagem: um dizer raro, que dá acesso à "região da vida possível", antes intocada.

O dizer desacostumado e raro de Gombro é preciso, tem a precisão de uma palavra "necessária" ${ }^{39}$, que não imita, que não alenta, mas mantém-se inflada de vida possível. Assim poderia vencer

a palavra morta, a palavra bom-senso, a palavra psi, a palavra língua ordinária, a palavra jornal, a palavra divã, a palavra belas-letras, a palavra homem-de-letras, a palavra amiga a palavra diversão, a palavra talk-show, a palavra toda-TV e toda-rádio [...], a palavra materna, a palavra ciência, a palavra diagnóstico, a palavra humanista, a palavra moral-polícia; é um bando, é um séquito interminável o das palavras que eu preciso silenciar. ${ }^{40}$

Isso porque a escrita se lança para fora da série, para fora do ciclo alimentado pelos que obrigam a dizer, pelos que disseminam a oferta e a demanda infinita de sentido. A escrita faz furo nessa roda das repetições, trazendo o seu fora Escrever, impondo silêncio às palavras inchadas de significado, para fazer brotar a voz "lavada pelo fogo", que torna "os

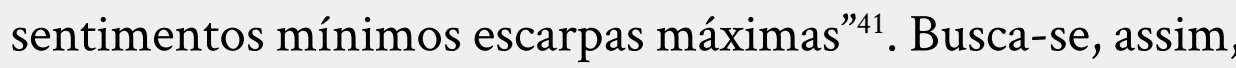
um dizer mínimo que desloque as relações com o eu e com as coisas do mundo, criando uma sociabilidade outra, no ponto da incandescência.

Contra um eu que pesa sobre a linguagem, comprimindo as possibilidades de abertura da língua e de criação de modos de vida desviantes, Juliano Pessanha diz de grito ou de uma palavra que escapa, ou despenca: desajustam a organização burocrática da língua e a operação higiênica, embora excessiva, da comunicação diária contemporânea. Deseja-se o que desembrulha o corpo da língua, fazendo-a chiar.

De acordo com o que se lê em suas obras, uma das maneiras de devolver a possibilidade de realmente termos algo a dizer é pela palavra literária, que, junto à recusa à conectividade exacerbada - em direção a uma solidão absoluta -, inscreve um dizer outro; reencontro com o que fisga o corpo e com as coisas do mundo em estado de celebração, o mar, a areia, as pedras que varreriam seus olhos a ponto de cegar. Esse encontro só poderia ser abordado por meio do idioma desconhecido de uma heterotanatografia.

EM TESE $\quad$ BELO HORIZONTE $\quad$ v. $19 \quad$ N. $1 \quad$ JAN.-ABR. $2013 \quad$ LABANCA. Pela rugosidade da vida: a solidão e a escrita como rotas [.... $\quad$ P. $76-84$


42. PESSANHA. Sabedoria do nunca, p. 62.
Por isso, se Juliano Pessanha utiliza, ele mesmo, a expressão "rota de fuga" é para abordar os modos de vida criados para escapar de uma vida tornada um grande cosmético. Aponta, então, a escrita e a solidão como caminhos que permitem o emergir das singularidades - uma rugosidade. Tais vias, porém, convergem para a rota do silenciamento. A solidão e a escrita literária fazem parte de um silenciar como tarefa necessária sobretudo ao homem contemporâneo: rarefazer as falas, as imagens, os vínculos, em direção a um encontro mais consistente com o outro, porque despossuído do excesso de palavras e demandas que regem as regras do "bom" comportamento. Só assim tecer uma nova abordagem do outro, cujo encontro faça florescer uma "costura amorosa"42 que contamine pelas distâncias e continue ressoando - em toda parte e onde houver vida.

\section{REFERÊNCIAS}

CASTELLO BRANCO, Lúcia. Os absolutamente sós. Llansol - A letra - Lacan. Belo Horizonte: Autêntica; FALE/UFMG, 2000.

DELEUZE, Gilles. Conversações. Trad. Peter Pal Pelbart. Rio de Janeiro: Editora 34, 1992.

DELEUZE, Gilles. Crítica e clínica. Trad. Peter Pál Pelbart. São Paulo: Ed. 34, 1997.
JARDIM, Alex Fabiano Correia. Impessoalidade e modos de vida em Gilles Deleuze: breves considerações. Unimontes científica. Montes Claros, v.6, n.1, jan./jun. 2004

PANADÉS, Julia. Método. In: Pausa. Junho de 2013.

PELBART, Peter Pál. Como viver só. Catálogo da 27ª Bienal de São Paulo. Rio de Janeiro: Cobogó, 2008. p. 266-276.

PELBART, Peter Pál. Prefácio. In: PESSANHA, Juliano Garcia. Certeza do Agora. Cotia, SP: Ateliê Editorial, 2006. p. 13-16.

PELBART, Peter Pál. Vida Capital. Ensaios de Biopolítica. São Paulo: lluminuras, 2009

PESSANHA, Juliano Garcia. Certeza do Agora. Cotia, SP: Ateliê Editorial, 2006

PESSANHA, Juliano Garcia. Instabilidade perpétua. São Paulo: Ateliê Editorial, 2009

PESSANHA, Juliano Garcia. Sabedoria do nunca. Cotia, SP: Ateliê Editorial, 1999.

RAMOS, Nuno. Ó. São Paulo: lluminuras, 2008.

RAMOS, Nuno. O mau vidraceiro. São Paulo: Globo, 2010.

STAROBINSKI, Jean. Jean-Jacques Rousseau. A transparência e o obstáculo. Trad. Maria Lúcia Machado. São Paulo: Companhia das Letras, 2011 